\title{
Use of angiotensin receptor - neprilysin inhibitors in heart failure: a paradigm shift
}

\author{
MOE Irhuma*, M Vally
}

Division of Clinical and Experimental Pharmacology, Department of Pharmacy and Pharmacology, School of Therapeutic Sciences, Faculty of Health Sciences, University of Witwatersrand, Johannesburg

*Corresponding author, email: mohamed.irhuma@wits.ac.za

\begin{abstract}
Heart failure is a clinical syndrome responsible for at least one-third of hospitalisations amongst cardiac patients, with escalating mortality and healthcare costs on both public and private health care. Both prevalence and incidence of heart failure increase steeply with advancing age, making it a growing public health problem. Pathophysiologically, heart failure clinically presents in two common forms: heart failure with preserved ejection fraction and heart failure with reduced ejection fraction. The cornerstone of heart failure management includes the use of angiotensin-converting enzyme inhibitors. A recently developed pharmacotherapy that inhibits both the angiotensin receptor and the enzyme neprilysin has shown promise in the management of heart failure with reduced ejection fraction. This article will highlight the impact of this new therapy and its potential use in heart failure with reduced ejection fraction.
\end{abstract}

Keywords: ACE-inhibitors, angiotensin receptor blockers, ARBs, enalapril, heart failure, HFrEF management, neprilysin inhibitors, sacubitril, valsartan

\section{Introduction}

Heart failure (HF) is defined as a clinical syndrome where the heart fails to maintain cardiac output to meet physiological demands and accommodate venous return. HF represents a public health problem, with large inflation in both disease prevalence and treatment cost. ${ }^{1}$ With the current advances in acute coronary care as well as increasing efficacy in the treatment of coronary artery disease, more patients now survive acute coronary events. ${ }^{1,2}$ This has resulted in a steady increase in the number of patients with chronic HF.1,2 The disease progressively worsens and results in significant morbidity and premature cardiac death. ${ }^{2}$ The common pathophysiological types of HF include heart failure with preserved ejection fraction (HFpEF) and heart failure with reduced ejection fraction (HFrEF). ${ }^{2}$ This article will briefly highlight the impact of using neprilysin inhibitors in HFrEF.

\section{Heart failure with reduced ejection fraction}

The most common causes of HFrEF are resistant hypertension (blood pressure that remains above goal in spite of the concurrent use of three antihypertensive agents of different classes), and ischaemic heart disease (IHD).,4 Less common causes include cardiomyopathy, valvular disorders, myocarditis and the use of cardiotoxic therapies. ${ }^{1,3}$ While the pathophysiology of this form of HF has long been understood, one of the main neurohormonal compensatory mechanisms is the rennin angiotensin aldosterone system (RAAS). ${ }^{2}$
The RAAS system is responsible for a cascade of hormones which produce effects on the heart, kidneys and systemic vasculature. $^{2}$ This is all done in an attempt to reverse the adverse reactions of $\mathrm{HF}^{2}$ It is important to note that continuous and vigorous stimulation of this pathway will be deleterious and often permanently changes the patient's cardiovascular physiology. ${ }^{2}$ These hormones produce a cellular proliferative effect on cardiac myocytes, as well as increasing cell apoptosis and fibroblast activity. ${ }^{5,6}$ This could result in the replacement of healthy myocardial tissue with non-contractile fibrotic tissue, and progress to ventricular remodelling. ${ }^{5,6}$ Angiotensin II and aldosterone both increase sodium and water retention which then increase intravascular volume leading to an increase in blood pressure and worsening of systemic (cardiopulmonary) congestion. ${ }^{78}$ In addition to this, the combination of angiotensin II and sympathetic hyperactivity usually results in enhanced peripheral vascular resistance and further contributes to increased blood pressure. The net effect results in an increased strain on the heart and sets up a cycle of steadily diminishing left ventricular function. ${ }^{9}$

The heart does, however, have a compensatory mechanism to counteract the effects of RAAS, which come in the form of natriuretic peptides (NPs). ${ }^{10}$ NPs present as four different types and their effects include maintaining cardio-renal homeostasis through induction of diuresis and natriuresis, as well as vasodilation and inhibition of the sympathetic nervous system. ${ }^{11}$ NPs are metabolised by an enzyme called neprilysin through an 
enzymatic cleavage process. ${ }^{12}$ Whlist NPs exhibit limited counterregulatory effects on the RAAS, they are, however, no match for RAAS which has more potent effects. ${ }^{2}$

\section{Angiotensin-converting enzyme inhibitors and angiotensin receptor blockers in heart failure}

Taking into account the effects of the RAAS on patients with HF, especially those with $\mathrm{HFrEF}$, it stands to reason that the blockade of the RAAS system would be a key component towards successful therapy. ${ }^{13}$

The angiotensin-converting enzyme inhibitors (ACE-inhibitors), like enalapril, block the RAAS system by preventing the conversion of angiotensin I to angiotensin II. The ACE-inhibitors have been the cornerstone of the pharmacotherapy of HF with reduced ejection fraction for more than two and a half decades (CONSENSUS 1987), ${ }^{14}$ ever since they were shown to reduce risk of death in these patients. ${ }^{15}$ Chronic use of enalapril also reduces the relative risk of death by $16 \%$ in patients with mild to moderate symptoms of HF. ${ }^{15}$ The common adverse effects associated with the ACE-inhibitors treatment include the bradykinin-induced cough, angioedema and hyperkalaemia. ${ }^{16}$

Angiotensin receptor blockers (ARBs) block the binding of angiotensin II to the angiotensin II Type $1\left(A T_{1}\right)$ receptor. ${ }^{2}$ Whilst it was previously thought that ARBs would be superior to the ACEinhibitors in the management of $\mathrm{HF}$, the results of trials have been inconsistent. ${ }^{15}$ Thus the ACE-inhibitors are the preferred first-line therapy for the management of HFrEF when compared to the ARBs. Moreover, ARBs are only preferred to ACE-inhibitors in patients who develop intolerance to the ACE-inhibitors therapy in the form of the bradykinin-induced cough. ${ }^{15}$ However, ARBs are not recommended for patients who develop hyperkalaemia or renal insufficiency as a result of ACE-inhibitor therapy. ${ }^{17}$ Such situations carry the same risk regardless of whether an ACE-inhibitor or an ARB is used..$^{16}$ In the previous clinical trials investigating the role of $A R B s$ in $\mathrm{HF}$, the two drugs that have been studied the most were valsartan and candesartan. ${ }^{18,19}$

\section{Neprilysin inhibitors in heart failure}

The enzyme neprilysin is responsible for the degradation and inactivation of the NPs. ${ }^{12}$ Neprilysin also inactivates other endogenous vasoactive peptides like bradykinin, substance $P$, oxytocin and adrenomedullin. Inhibition of neprilysin increases NPs, bradykinin and adrenomedullin and counters the effects of the RAAS system, reducing vasoconstriction, sodium retention and maladaptive remodelling of the heart. ${ }^{20,21}$

It would thus seem like an excellent idea to structure pharmacotherapy using a combination of an agent that blocks the RAAS system with another agent that inhibits neprilysin. The combination of ACE-inhibitors and neprilysin inhibitors was shown to be superior when compared to their individual effects in experimental studies, however, clinical trials using a combination of these two agents were associated with serious adverse events like angioedema. ${ }^{22-25}$ The angioedema, as an outcome of the combination of omapatrilat (neprilysin inhibitor) and the ACE-inhibitors, was attributed to the inhibitory effects of all three enzymes that are responsible for bradykinin breakdown, namely $\mathrm{ACE}$, neprilysin and aminopeptidase P. ${ }^{26}$ In order to minimise such a serious adverse effect, a specific neprilysin inhibitor agent, sacubitril, was used, to be combined with the ARB valsartan. ${ }^{15}$ This combination does not inhibit ACE or aminopeptidase P. ${ }^{15}$

\section{Angiotensin-neprilysin inhibitors (sacubitril- valsartan)}

Sacubitril-valsartan is an angiotensin receptor-neprilysin inhibitor, combining the angiotensin II receptor blocker (valsartan) and the neprilysin inhibitor (sacubitril). ${ }^{15}$ The combination of valsartan and sacubitril (a neprilysin inhibitor) was investigated in comparison to enalapril in patients with HFrEF (PARADIGM-HF trial). ${ }^{15}$ This was a randomised doubleblind trial, with the primary outcome being a composite of death from cardiovascular causes or hospitalisation for HF, and was designed to detect a difference in the rates of death from cardiovascular causes. ${ }^{15}$ In this randomised controlled trial, 8399 patients (who completed the trial) with a left ventricular ejection fraction (LVEF) of $\leq 40 \%$ and a New York Heart Association (NYHA) functional classification of II, III or IV were randomised to one of two groups. One group received the combination of sacubitril-valsartan (LCZ696) twice daily and the other enalapril twice daily. ${ }^{15}$ The trial had to be stopped early, after a median time period of 24 months because the preset boundary for early termination for benefit had been crossed. ${ }^{15}$ Table I summarises the findings of the trial.

Table I: Findings of the PARADIGM-HF trial ${ }^{15}$

\section{The PARADIGM-HF trial found that:}

1. Sacubitril-valsartan reduced the primary outcome of death from cardiovascular disease or hospitalisation for HF ( $21.8 \%$ vs. $26.5 \%$; hazard ratio [HR] 0.80; 95\% Cl 0.73-0.87).

2. Sacubitril-valsartan reduced the risk of death compared to enalapril (17\% vs. $19.8 \%$; HR $0.84 ; 95 \% \mathrm{Cl} 0.76-0.93$ ).

3. Sacubitril-valsartan also reduced the risk of death from cardiovascular causes ( $13.3 \%$ vs. $16.5 \% \mathrm{HR} 0.80 ; 95 \% \mathrm{Cl} 0.71-0.80$ ).

4. Sacubitril-valsartan reduced the risk of hospitalisation for HF (12.8\% vs. $15.6 \%$; HR 0.79; $95 \% \mathrm{Cl} 0.71-0.89$ ).

5. There were higher rates of hypotension and non-serious angioedema in the sacubitril-valsartan group compared to the enalapril group.

6. There were lower rates of renal impairment, hyperkalaemia, and cough in the sacubitril-valsartan group compared to the enalapril group.

The results from this trial confirmed the superiority of the sacubitril-valsartan combination over enalapril, such combination was not accompanied by important safety concerns in patients with chronic HF.

This drug regimen as yet is still not registered in South Africa, but the FDA has recommended that it be used in patients with chronic NYHA functional class II-IV with HFrEF. ${ }^{27}$ The important clinical pharmacology information is listed in Table II. 
Table II: Important clinical pharmacology data of the combination of sacubitril-valsartan

\begin{tabular}{|c|c|c|c|c|}
\hline Indication & Dosing & Contraindications & Adverse effects & Special prescriber points \\
\hline $\begin{array}{l}\text { Sacubitril-valsartan is for } \\
\text { use in patients with NYHA } \\
\text { functional class II to IV } \\
\text { HFrEF. }{ }^{27} \\
\text { Note: } \\
\text { The drug is administered } \\
\text { in conjunction with other } \\
\text { HF therapies but in place } \\
\text { of an ACE-inhibitor or an } \\
\text { ARB. }\end{array}$ & $\begin{array}{l}\text { The sacubitril-valsartan } \\
\text { combination tablet comes } \\
\text { in doses of } 26 \mathrm{mg}, 51 \mathrm{mg} \text {, } \\
\text { and } 103 \mathrm{mg} \text { of valsartan } \\
\text { in the combination tablet } \\
\text { which is equivalent to } \\
40 \mathrm{mg}, 80 \mathrm{mg} \text {, and } 160 \\
\mathrm{mg} \text { of valsartan in other } \\
\text { formulations. } \\
\text { Note: } \\
\text { Do not administer within } \\
36 \text { hours of switching to or } \\
\text { from an ACE-inhibitor. }\end{array}$ & $\begin{array}{l}\text { - Known hypersensitivity. } \\
\text { - Patient with a history of } \\
\text { angioedema to ACEs or } \\
\text { ARBs. } \\
\text { - Pregnant patients. } \\
\text { - Concomitant use with } \\
\text { ACE-inhibitors (due } \\
\text { to increased risk of } \\
\text { angioedema). }\end{array}$ & $\begin{array}{l}\text { - Hypotension was a } \\
\text { common adverse } \\
\text { effect reported in the } \\
\text { PARADIGM-HF trial. } .^{15} \\
\text { - Another common } \\
\text { adverse effect was } \\
\text { hyperkalaemia. }{ }^{15} \\
\text { - Cough was less common } \\
\text { when compared to } \\
\text { enalapril. }{ }^{15}\end{array}$ & $\begin{array}{l}\text { Measures to reduce the } \\
\text { risk of hypotension include } \\
\text { correcting volume depletion } \\
\text { prior to starting, and starting } \\
\text { at a lower dose. } \\
\text { In patients receiving any } \\
\text { regimen including one or } \\
\text { more inhibitors of the RAAS, } \\
\text { precautions should be taken } \\
\text { to avoid hyperkalaemia. } \\
\text { Screen patients for baseline } \\
\text { renal dysfunction or } \\
\text { hyperkalaemia, and close } \\
\text { periodic monitoring of } \\
\text { renal function and serum } \\
\text { potassium concentration is } \\
\text { required. }\end{array}$ \\
\hline
\end{tabular}

\section{Beyond heart failure}

Sacubitril-valsartan was also investigated as a treatment modality in patients with hypertension. ${ }^{2}$ A trial was conducted with 1300 patients with mild to moderate hypertension, who were randomised and either given the combination therapy of sacubitril-valsartan, or sacubitril alone, or a placebo, or equivalent doses of valsartan to the sacubitril-valsartan combination. ${ }^{28}$ The secondary outcomes of the study included systolic blood pressure reduction, pulse pressure, ambulatory blood pressure, safety parameters and measurement of markers of other cardiovascular diseases. There was significant reduction in blood pressure in patients taking the sacubitril-valsartan at doses of 200 and $400 \mathrm{mg}(-5 /-3 \mathrm{mmHg}$ and $-6 /-3 \mathrm{mmHg}$ respectively) when compared to equivalent doses of valsartan alone. ${ }^{28}$ This effect was also seen in the patient ambulatory blood pressure readings. The blood pressure reduction conferred by sacubitrilvalsartan $400 \mathrm{mg}$ when compared with the bioequivalent doses of its components (200 mg sacubitril or $320 \mathrm{mg}$ of valsartan) was fully additive in diastolic blood pressure reduction and even more additive in systolic blood pressure reduction. This confirms the complementary effects of inhibiting RAAS and neprilysin simultaneously. ${ }^{28}$

Sacubitril-valsartan was also studied in patients with renal impairment and post myocardial infarctions. ${ }^{2}$ Sacubitril-valsartan has shown to reduce cardiac weight and fibrosis in the peri-infarct and remote myocardium when compared to placebo. ${ }^{29,30}$ It also lowered left ventricular end-diastolic diameter, increased left ventricular ejection fraction and increased circular and diastolic wall strain after a four week period. 29,30 Whilst these results are promising there have not been any clinical studies done as yet. ${ }^{2}$

\section{Conclusion}

The number of patients with chronic HF is increasing. ${ }^{1,2}$ The search is on for new rational therapeutic modalities to treat this condition and prevent early mortality. The current mainstay of treatment in patients with HFrEF is enalapril, with the use of ARBs discouraged unless the patient is intolerant to the ACEinhibitor. The angiotensin-neprilysin inhibitor combination of valsartan-sacubitril has shown promise in the PARADIGM-HF trial in reducing the primary outcome of death from cardiovascular disease, or hospitalisation for HF when compared to enalapril, and was not associated with any serious adverse events. ${ }^{14}$ Whilst sacubitril-valsartan has shown such promising results, enalapril should still be the preferred first-line treatment choice in patients with $\mathrm{HFrEF}$ as more studies are still required on this drug combination. Moreover, the sacubitril-valsartan combination has also shown promise in the future pharmacotherapy of hypertension and ischaemic heart disease. These, however, require further investigation in well-established randomised clinical trials.

\section{References}

1. Kemp D, Conte JV. The pathophysiology of heart failure. Cardiovasc Pathol.2013;21(5):365-371

2. Singh JS, Lang CC. Angiotensin receptor-neprilysin inhibitors: clinical potential in heart failure and beyond. Vasc Health Risk Manag. 2015;11:283-95.

3. Go AS, Mozaffarian D, Roger VL, et al. Heart disease and stroke statistics-2014 update: a report from the American Heart Association. Circulation. 2014;129(3):e28-e292. doi: 10.1161/01

4. McMurray JVV, Pfeffer MA. Heart failure. Lancet. 2005:365(9474):1877-1889.

5. Weber KT. Extracellular matrix remodeling in heart failure: a role for de novo angiotensin II generation. Circulation. 1997;96(11):4065-82.

6. Peng J, Gurantz D, Tran V, Cowling RT, et al. Tumor necrosis factor-alpha-induced $A T_{1}$ receptor upregulation enhances angiotensin II-mediated cardiac fibroblast responses that favor fibrosis. Circ Res. 2002;91(12):1119-26.

7. Bart BA. Treatment of congestion in congestive heart failure: ultrafiltration is the only rational initial treatment of volume overload in decompensated heart failure. Circ Heart Fail. 2009;2(5):499-504.

8. Schrier RW. Role of diminished renal function in cardiovascular mortality: marker or pathogenetic factor? J Am Coll Cardiol. 2006;47(1):1-8.

9. Atlas SA. The renin-angiotensin aldosterone system: pathophysiological role and pharmacologic inhibition. J Manag Care Pharm. 2007;13(8 Suppl B):9-20.

10. McKie PM, Burnett JC Jr. Rationale and therapeutic opportunities for natriuretic peptide system augmentation in heart failure. Curr Heart Fail Rep.2015;12(1):7-14.

11. Nathisuwan S, Talbert RL. A review of vasopeptidase inhibitors: a new modality in the treatment of hypertension and chronic heart failure. Pharmacotherapy. 2002;22(1):27-42.

12. Stein $B C$, Levin RI. Natriuretic peptides: physiology, therapeutic potential, and risk stratification in ischemic heart disease. Am Heart J. 1998;135(5 Pt 1):914-23.

13. Yancy CW, Jessup M, Bozkurt B, et al. 2013 ACCF/AHA guideline for the management of heart failure: a report of the American College of Cardiology Foundation/American Heart Association Task Force on Practice Guidelines. J Am Coll Cardiol. 2013;62(16):e147-239.

14. Effects of enalapril on mortality in severe congestive heart failure. Results of the Cooperative North Scandinavian Enalapril Survival Study (CONSENSUS). The CONSENSUS Trial Study Group. N Engl J Med. 1987;316(23):1429-35. 
15. McMurray JJ, Packer M, Desai AS, et al; PARADIGM-HF Investigators and Committees. Angiotensin-neprilysin inhibition versus enalapril in heart failure. $\mathrm{N}$ Engl J Med. 2014; 371(11):993-1004.

16. Brunton LB, Chabner BA, Knollmann BC, eds. Goodman \& Gilman's The Pharmacological Basis of Therapeutics. 12 ${ }^{\text {th }}$ ed. New York: McGraw-Hill; 2011.

17. Goldsmith DJ. Angiotensin receptor antagonists. Lancet.1997;349:1255.

18. Cohn JN, Tognoni G. Valsartan Heart Failure Trial Investigators. A randomized trial of the angiotensin-receptor blocker valsartan in chronic heart failure. $\mathrm{N}$ Engl J Med. 2001; 345(23):1667-75.

19. McMurray JJ, Ostergren J, Swedberg K, et al. Effects of candesartan in patients with chronic heart failure and reduced left-ventricular systolic function taking angiotensin-converting-enzyme inhibitors: the CHARM-Added trial. Lancet. 2003;362(9386):767-71.

20. Maric C, Zheng W, Walther T. Interactions between angiotensin II and atrial natriuretic peptide in renomedullary interstitial cells: the role of neutral endopeptidase. Nephron Physiol. 2006;103(3):p149-56.

21. Kuhn M. Molecular physiology of natriuretic peptide signalling. Basic Res Cardiol. 2004;99(2):76-82.

22. Rademaker MT, Charles CJ, Espiner EA, Nicholls MG, et al. Combined neutral endopeptidase and angiotensin-converting enzyme inhibition in heart failure: role of natriuretic peptides and angiotensin II. J Cardiovasc Pharmacol. 1998;31(1):116-25.

23. Trippodo NC, Fox M, Monticello TM, Panchal BC, et al. Vasopeptidase inhibition with omapatrilat improves cardiac geometry and survival in cardiomyopathic hamsters more than does ACE inhibition with captopril. J Cardiovasc Pharmacol. 1999;34(6):78290.
24. Packer M, Califf RM, Konstam MA, Krum H, et al. Comparison of omapatrilat and enalapril in patients with chronic heart failure: the Omapatrilat Versus Enalapril Randomized Trial of Utility in Reducing Events (OVERTURE). Circulation. 2002;106(8):920-6.

25. Kostis JB, Packer M, Black HR, Schmieder R, et al. Omapatrilat and enalapril in patients with hypertension: the Omapatrilat Cardiovascular Treatment vs. Enalapril (OCTAVE) trial. Am J Hypertens. 2004; 17(2):103-11.

26. Fryer RM, Segreti J, Banfor PN, et al. Effect of bradykinin metabolism inhibitors on evoked hypotension in rats: rank efficacy of enzymes associated with bradykinin-mediated angioedema. Br J Pharmacol. 2008;153(5):947-55.

27. http://www.accessdata.fda.gov/drugsatfda_docs/label/2015/2076200rig1 s000lbl.pdf (Last accessed 27th June 2016)

28. Ruilope LM, Dukat $A$, Böhm M, Lacourcière $Y$, et al. Blood-pressure reduction with LCZ696, a novel dual-acting inhibitor of the angiotensin II receptor and neprilysin: a randomised, double-blind, placebo-controlled, active comparator study. Lancet. 2010;375(9722):1255-66.

29. Von Lueder TG, Wang B, Kompa A, Webb R, et al. Angiotensin-receptor neprilysininhibition (ARNi) attenuates ischemic cardiac failure in vivo and angiotensin-IIinduced cellular cardiac hypertrophy and fibrosis. Global Heart. 2014;9(1 Suppl 1):e237.

30. von Lueder TG, Wang BH, Kompa AR, et al. The angiotensin-receptor neprilysin inhibitor LCZ696 attenuates cardiac remodeling and dysfunction after myocardial infarction by reducing cardiac fibrosis and hypertrophy. Circ Heart Fail. 2015;8(1):71-78.

\section{Suid-Afrikaanse Noodhulpliga}

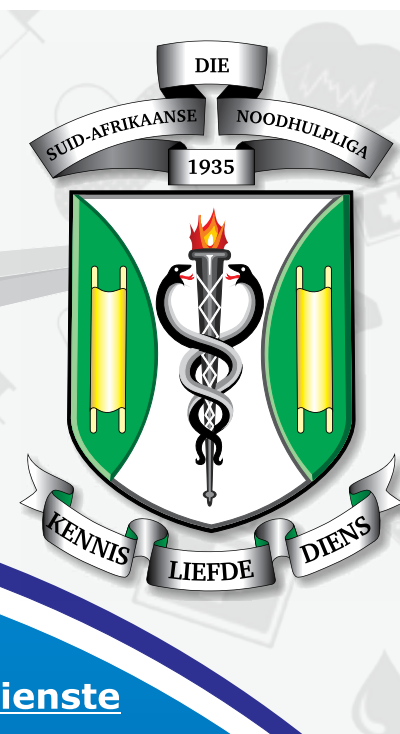

\section{Noodhulp stap vir stap}

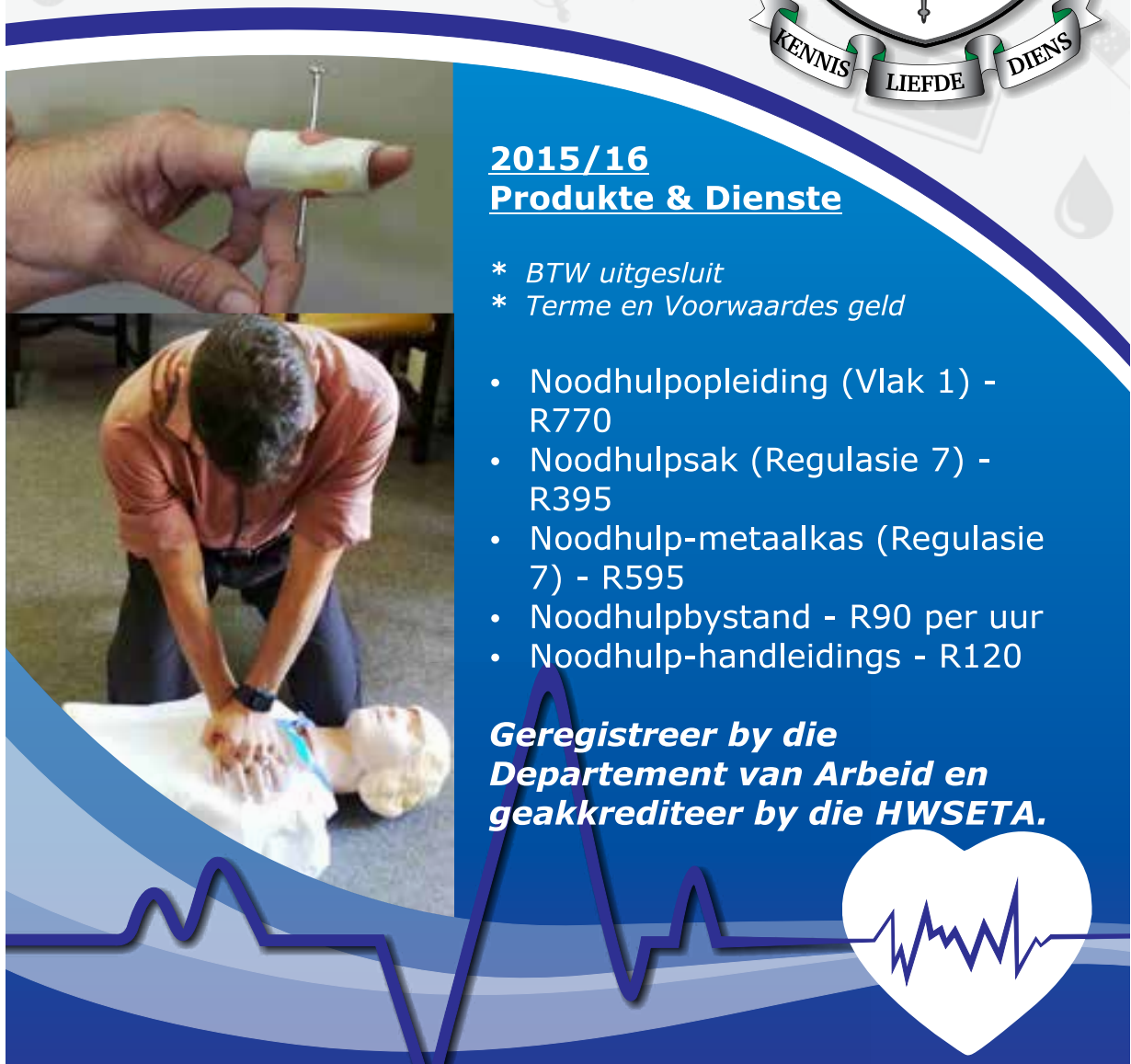

